УДК 338.2

DOI 10.17308/econ.2020.1/2762

\title{
СОВЕРШЕНСТВОВАНИЕ МОДЕЛИ УПРАВЛЕНИЯ ЭКОНОМИЧЕСКОЙ СИСТЕМОЙ НА ОСНОВЕ САМООРГАНИЗАЦИИ, СИНЕРГЕТИЧЕСКОГО ЭФФЕКТА И ГОРИЗОНТАЛЬНОГО ВЗАИМОДЕЙСТВИЯ СУБЪЕКТОВ РЫНКА
}

\author{
А. А. Гершанок, Е. А. Малышев \\ Пермский государственный национальный исследовательский университет
}

Поступила в редакцию 10 декабря 2019 г.

\begin{abstract}
Аннотация: на основе проведенных исследований и аналитической информации рассматриваются причины отставания в организационном развитии национальной экономической системы от зарубежных в условиях качественного роста и глобализации экономики. Показаны существуюшие организационные недостатки действующей модели управления экономической системой в РФ. В связи со значительным ускорением научно-технического прогресса отмечается переход в высокоразвитых странах от организащионных структур масштабной экономики к самоорганизующимся структурам качественной экономики. Доказана зависимость темпов роста ВВП от надлежсащего порядка в экономической системе. Предложена новая модель управления экономической системой в современных условиях, основанная на самоорганизации, синергетическом эффекте и горизонтальном взаимодействии субъектов рынка.
\end{abstract}

Ключевые слова: экономическая система, качественный рост, порядок в экономической системе, организационное развитие, диссипативная среда, энтропия и негэнтропийные процессы в экономической системе, самоорганизациия.

\begin{abstract}
: on the basis of the conducted researches and analytical information the reasons of lagging behind in organizational development of national economic system from foreign in the conditions of qualitative growth and globalization of economy are considered. The existing organizational shortcomings of the current model of economic system management in the Russian Federation are shown. Due to the significant acceleration of scientific and technological progress, the transition from organizational structures of largescale economy to self-organizing structures of high-quality economy is noted in highly developed countries. The dependence of GDP growth rates on the proper order in the economic system is proved. A new model of economic system management in modern conditions is proposed, based on self-organization, synergetic effect and horizontal interaction of market subjects.
\end{abstract}

Key words: economic system, qualitative growth, order in the economic system, organizational development, dissipative environment, entropy and negentropy processes in the economic system, self-organization.

Рыночные реформы, осуществляемые в Российской Федерации в 1990-е, 2000-е, 2010-е гг. с целью сформировать современную и эффективную экономическую систему, устойчиво развивающуюся, не зависящую от сырьевых ресурсов, по-прежнему не дают желаемого результата. При этом следует отметить, что за это время в мировой экономической системе произошли существенные изменения: доля качественной экономики в общем

(C) Гершанок А. А., Малышев Е. А., 2020 объеме производства выросла в десятки раз. Если доля инновационной продукции в США составляет 30-40\% (доходя до 80-90 \% в некоторых отраслях экономики), то в России - 8,5 \% [1], что свидетельствует о фактическом выпадении России из мирового тренда.

Оценка уровня инновационной активности страны (региона) в мировой практике проводится посредством соответствующего индекса IAK (индекс инновационной активности), рассчитываемого как соотношение величины удельных затрат страны 
(региона) на исследования и разработки (на одного занятого) к аналогичному наибольшему показателю исследуемой выборки (для страны-лидера).

В целом индекс IAK показывает общий вес затрат государства на исследования и разработки, инновации по всем секторам экономики (рис. 1).

Расчёт индекса произведён на основе открытых данных по затратам стран мира на исследования и разработки, России $[2 ; 3]$, а также по численности занятого населения (рабочей силы) в странах мира [4].

Приведённые данные (рисунок) свидетельствуют о том, что инновационная составляющая в структуре экономики России остаётся на крайне низком уровне (19\% от уровня США). При этом увеличение доли инноваций идёт гораздо медленнее, чем позволяет инновационный потенциал страны.

Данная проблема связана с тем, что, во-первых, в экономике России имеются текущие негативные изменения, вызванные в том числе объективными внешними факторами [5], а во-вторых, - с неоправданно медленными и неэффективными структурными сдвигами в инновационной сфере [6]. Помимо сказанного, необходимо отметить наличие неэффективных механизмов коммерциализации инноваций, слабую инновационную активность и низкий спрос на инновации со стороны частного бизнеса, отсутствие поддержки отраслевых бизнес-ассоциаций, позволившей бы активно стимулировать инновационную деятельность.

Остаётся нерешённым и кадровый вопрос. Наблюдается постоянное снижение численности высококачественного персонала в сфере НИОКР, ухудшается качество среднего и высшего образования [7].
Подобные проблемы, которые не решались десятилетиями, а также сохраняющийся сырьевой характер российской экономики приводят к замедлению инновационного роста [8] и существенному отставанию России от развитых стран, лидирующих в сфере инноваций (США, Швеции, Германии, Японии, Кореи, Тайваня и т. п.).

Согласно методологии анализа инновационных систем стран мира, предложенной совместно консорциумом Корнельского университета (США), Школой бизнеса INSEAD (Франция) и Всемирной организацией интеллектуальной собственности (ВОИС), для оценки инновационной активности стран и эффективности инноваций используется глобальный инновационный индекс - GII.

Рейтинг 2016 г., как и в 2015 г., по-прежнему возглавили Швейцария, Швеция, Великобритания, США и Финляндия. При этом на 5 пунктов поднялась Россия и заняла 43-е место [9, с. 20].

Рейтинг, основанный на расчете глобального инновационного индекса, включает 82 различных показателя, в том числе результативность инноваций, потенциал, рамочные условия инновационной деятельности, уровень развития институтов, экономика знаний, человеческий капитал, объём научных исследований, инфраструктура, развитость внутреннего рынка, бизнеса, технологий, результаты креативной деятельности и пр.

Сам индекс GII рассчитывается как среднее значение двух субиндексов:

1) ресурсов инноваций, основанного на расчете располагаемых ресурсов и условий для реализации инноваций: человеческий капитал и наука, инфраструктура, институты, развитие бизнеса, развитие внутреннего рынка;

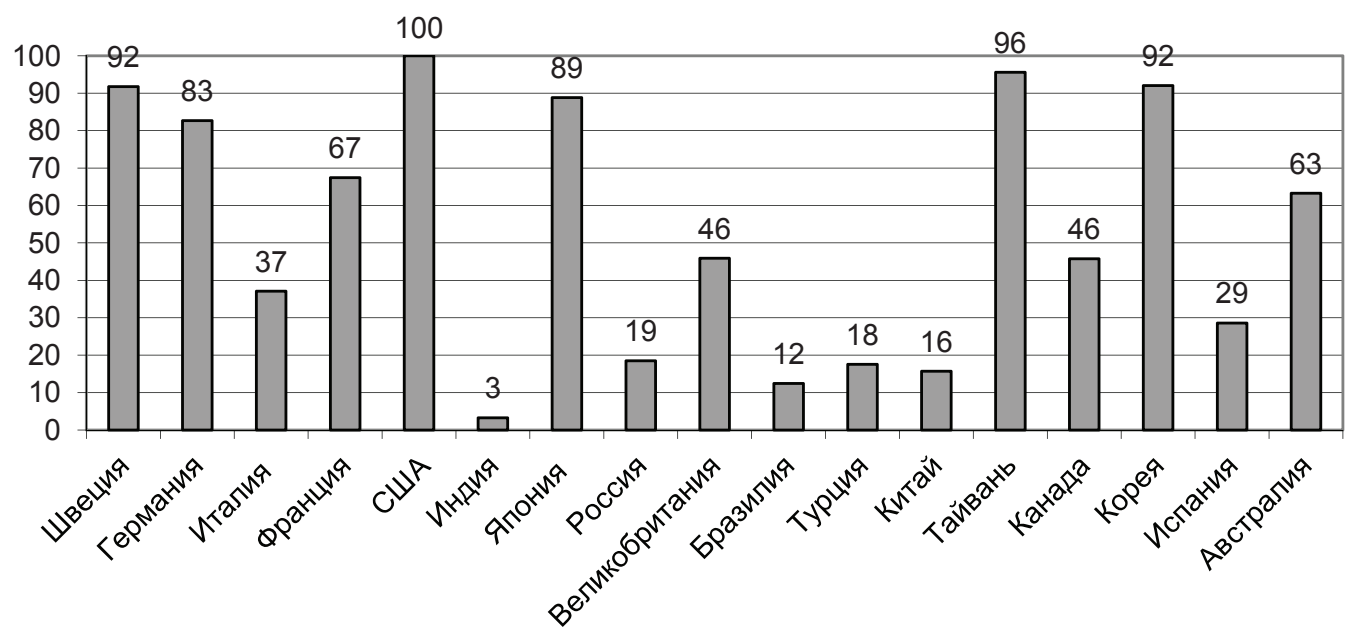

Рисунок. Инновационная активность (индекс) по странам, \% 
2) результатов инноваций, основанного на расчете достигнутых практических результатов осуществления инноваций: развитие креативной деятельности, развитие технологий, развитие экономики знаний.

Помимо самого индекса GII, может быть рассчитан коэффициент эффективности инноваций, определяемый как соотношение субиндекса результатов инноваций и субиндекса ресурсов инноваций. Коэффициент в итоге отражает агрегированную результативность инновационной деятельности при данном уровне инновационного потенциала.

В итоговом докладе «Глобальный инновационный индекс - 2017» Россия заняла уже 45-е место, несколько ухудшив свои позиции относительно 2016 г. [10, с. 20].

Однако, несмотря на стабильное улучшение индекса GII России с 2014 по 2016 г. (с 49-го по 43-е место) и незначительное ухудшение в 2017 г., по коэффициенту эффективности инновационной деятельности позиции страны остаются крайне слабыми: 69-е место в 2016 г., 75 -е место в 2017 г., что отражает недостаточно эффективную реализацию имеющегося инновационного потенциала страны [там же].

В целом проводимый курс прямого вмешательства государственных органов власти в экономический процесс вызывает недоверие и сомнение как с точки зрения правильности его выбора, так и в целом - пользы для граждан и общества. При этом транзакционные издержки по управлению этой громоздкой и неэффективной системой составляют более $40 \%$ ВВП (если раньше в СССР на 250 млн человек населения работал 1 млн чиновников, то сейчас в РФ на 140 млн человек работает 2,5 млн чиновников, которые трудятся в основном на удержание своей власти и взыскание с граждан «ренты»).

В настоящее время в РФ заметных положительных экономических результатов так и не наблюдается. Однако значительно возросли экспорт энергоресурсов и импорт продовольствия, техники, оборудования. Более того, после резкого сокращения в начале 1990-х гг. объёмов производства отечественных предприятий их экономические результаты не изменились и оставляют желать лучшего, что в свою очередь способствует ещё большему росту импорта, снижению конкурентоспособности экономики, росту социальной напряжённости.

Три периода девальвации рубля (1998, 2008 и 2014 гг.), с одной стороны, создали предпосылки для активизации развития российских предприятий за счёт роста цен на импортную продукцию, комплектующие, оборудование и т. п., но с другой привели к простому росту цен на отечественные товары без кардинального обновления производства, внедрения инноваций, развития человеческого капитала. В результате данные возможности были использованы крайне слабо, значительного роста объёмов промышленного производства, а следовательно и добавленной стоимости, не произошло. Все денежные средства ушли на предметы роскоши олигархов и малоэффективные PR-мероприятия (Сочи, Крым, ЧМ-2018 и т. д.) в рамках вертикально-интегрированной пирамидальной (фрактальной) экономики.

\section{Методы исследований, научная новизна}

Методологической и теоретической основой исследования послужили фундаментальные концепции и положения, представленные в классических и современных трудах отечественных и зарубежных ученых, статистические данные национальных и зарубежных агентств и институтов, эмпирические данные.

При проведении исследования эволюции экономических систем и организационных структур использованы следующие научные методы: моделирование, методы научной абстракции, абстрактного мышления, органически сочетающегося с конкретным представлением об объекте, его различных аспектах и процессах, методы структурно-функционального, исторического, логического, компаративного, статистического анализа и другие. В исследовании эффективности экономических систем особое внимание уделялось положениям общей теории систем, а в исследовании особенностей качественной экономики - принципам синергетики.

В основе проведенного исследования лежит обобщение практического опыта трансформации экономической системы России, а также развитых стран в условиях лавинного роста количества научно-технических открытий. При этом особенности трансформационных процессов, обусловленные различной степенью порядка и зрелости реформируемой экономики, степенью инновационного развития отдельных стран, предопределили трудности в использовании зарубежного опыта для разработки теоретических основ развития организационных структур. Определены проблемы переосмысления и адаптации зарубежного опыта к российской действительности, сформированы пути дальнейшего развития экономической системы РФ в условиях доминирования качественной экономики. 
Научная новизна исследования заключается в следующем:

- выявлены и проанализированы проблемы обеспечения устойчивого организационного развития национальной экономической системы;

- определена роль синергетических процессов в экономических системах;

- выявлены особенности трансформационных процессов, обусловленные различной степенью порядка и зрелости реформируемой экономики, степенью инновационного развития отдельных стран и открытостью экономических систем;

- уточнено понятие порядка в классической экономической системе на основе анализа его ключевых признаков;

- предложена экономико-математическая модель темпов роста национальной экономики, учитывающая влияние качества и исполнения институтов и других факторов в экономической системе.

Практическая ценность исследования объясняется тем, что теоретические положения и рекомендации, содержащиеся в работе, могут быть использованы для дальнейшего более глубокого изучения проблем обеспечения устойчивого организационного развития национальной экономической системы, повышения эффективности синергетических процессов. Полученные результаты могут способствовать качественному социально-экономическому развитию страны, адекватному развитию организационной структуры и системы управления процессами трансформации экономической системы России.

\section{1. Современные экономические системы в условиях качественного роста и глобальной экономики}

\section{1. Проблемы обеспечения устойчивого организационного развития национальной экономической системы}

Аналитическая информация по темпам роста реального ВВП РФ в сравнении с другими странами настраивает на поиск причин этого отрицательного явления. В частности, с 2011 по 2016 г. наблюдается негативная динамика, связанная с падением темпов роста реального ВВП до отрицательных величин [11]. Если в 2011 г. темпы роста реального ВВП России составляли 5,1 \%, то уже к 2014 г. они сократились до $0,7 \%$ и в 2015 г. составили отрицательную величину $--2,8 \%$ [12, с. 262$]$.

Проанализировав основные факторы, влияющие на темпы роста ВВП, можно выделить следующие: качество рабочей силы, индекс человеческого развития, индекс промышленного производ- ства. Для России подобные показатели оцениваются высоко: интеллектуальный показатель IQ = 97 [13], индекс человеческого развития $=0,78$ [14], индекс промышленного производства (по итогам 2017 г.) = 101,5 [15]. Цифры говорят о том, что потенциал есть.

Какова причина столь глобального отставания в темпах роста ВВП? Ключевой проблемой сложившейся ситуации является отставание РФ в организационном развитии экономической системы. Существующая модель организации в российской экономике была сформирована в условиях переходного периода от командной к рыночной экономике и уже давно выполнила поставленные перед ней задачи. Организационная структура нашей экономики долгое время не развивается. Задачи конкурентного качественного роста и глобальной экономики невозможно решить в действующей сегодня государственной вертикально-интегрированной организационной структуре. Остановимся на проблеме малой эффективности существующей организационной модели экономической системы. Существующая сегодня в РФ организационная модель экономической системы представляет собой модель вертикально-интегрированного государственного управления на основе крупных предприятий и не соответствует современным подходам к управлению экономической системой в условиях качественной экономики. Действующая модель пригодна только для управления линейными процессами в масштабном крупносерийном неинновационном производстве, но позволяет сохранять властные полномочия государственному аппарату, поскольку легче контролировать десятки крупных государственных предприятий, чем миллионы малых и средних самостоятельных предприятий частного капитала, причем существующая система управления в РФ является закрытой. Такое управление приносит выгоду только чиновникам. В этой схеме государственный аппарат управляет бизнесом, что в корне противоречит современным основам государственного устройства. В 2018 г. такая организационная структура является нелепостью - стрела времени давно прошла эту остановку. В чем причина такого отставания? Почему мы остановились на месте и находимся фактически в XIX в.?

Последние 50 лет можно охарактеризовать как взрыв научно-технического прогресса. Если раньше открытия в науке происходили довольно редко (5-6 открытий в 100 лет), то сейчас наблюдается лавинный процесс (до 1000 открытий в год). По 
этой причине устаревшие авторитарные методы управления неэффективны - мы не в состоянии предсказать следующие открытия. Новые открытия, как правило, происходят в процессе производства и поэтому в современных условиях бизнес должен управлять государственным аппаратом, а не наоборот, как в РФ, поскольку скорость в принятии адекватных решений в условиях жесткой глобальной конкуренции решает все. Как показывает практика, в условиях современной экономики наиболее эффективны с точки зрения управления процессы самоорганизации. Современная инновационная модель основывается на процессах открытости, самоорганизации и нелинейного развития, где предпочтение отдается малым и средним высокодинамичным инновационным предприятиям.

Согласно статистике малые предприятия вносят существенный вклад в развитие экономических систем стран - мировых лидеров. В настоящее время в США насчитывается порядка 17 млн предприятий малого бизнеса, которые создают 60 \% валового национального продукта. Порядка 95-98 \% предприятий в несельскохозяйственных отраслях экономики США - малые. Подобная структура функционирования экономической системы сложилась и во многих других странах. Такие страны, как Китай, Индонезия, Япония, Германия, имеют долю малого и среднего бизнеса в национальной экономике более 60 \%, тогда как Россия - менее 20 \%.

Применяемая сегодня в РФ модель управления давно устарела и пригодна для масштабного производства серийных товаров низкого потребительского качества. Современное конкурентное производство представляет собой деятельность высокоинтеллектуальных специалистов, работа которых основана на интуиции, новых знаниях и процессах самоорганизации без государственного вмешательства, т. е. это область качественной экономики. Качественная экономика отличается от экономики роста преобладанием творческой компоненты. Процесс творчества имеет лучшее развитие в организации, более ориентирован на горизонтальную творческую кооперацию предприятий, а не на существующие сегодня в РФ командные вертикально интегрированные модели управления. В современной качественной экономике успех приносят самоорганизующиеся мобильные малые и средние предприятия за счет синергетического эффекта, поскольку в диссипативной среде они максимально эффективны.

\section{2. Синергетические процессы и их роль в экономических системах}

Алгоритм появления нового изобретения и превращения его в инновационный продукт до сих пор является загадкой для человечества. Это явление происходит в основном случайно, или мы еще не знаем закономерностей, и не поддается прогнозированию [16; 17]. Природа неохотно расстаётся со своими тайнами. Для понимания процесса возникновения нового из существующих элементов Г. Хаккен создал новую науку - синергетику, а И. Пригожин разработал теорию диссипативных систем.

Синергетика открывает новые принципы создания нового сложного целого из известных частей, поясняя порядок построения сложных саморазвивающихся структур из простых. Объединение структур не сводится к простому их сложению, на самом деле имеет место переход на новый качественный уровень с эффектом возникновения новой энергии. Целое уже не равно сумме частей, оно не больше и не меньше суммы частей, оно качественно новое. Синергетика раскрывает закономерности и условия протекания быстрых, лавинообразных процессов и процессов нелинейного, самостимулирующего роста. Синергетику можно рассматривать как теорию образования новых качеств более высокого уровня [18, с. 45].

Синергетика выступает сегодня в качестве методологической основы для прогностической и управленческой деятельности в современном мире. Синергетика ориентирована на поиск неких универсальных законов эволюции открытых неравновесных систем любой природы [19]. Для генерации синергетического процесса необходимо наличие диссипативной среды и открытой системы. Термин «диссипация» образован от латинского dissipatio рассеиваю, разрушаю. Диссипати́вная система (структура) - распределенная физическая система, в которой происходит диссипация (рассеивание) энергии и возрастание энтропии. Все реальные среды, в том числе и экономическая среда, являются диссипативными средами. Важную роль играют неравновесные диссипативные среды, в которых потери энергии компенсируются ее притоком извне через внешние поля и потоки [20].

Диссипативную систему можно представить как некоторое устойчивое состояние в неравновесной среде при условии рассеивания энергии, поступающей извне. Диссипативная система фактически является неравновесной открытой системой. При определенном порядке в организации дисси- 
пативная система начинает работать эффективно. Эффективность системы достигается за счет максимального использования потенциала составляющих её элементов. Максимальная эффективность системы характеризуется отсутствием потерь в системе, т. е. рассеивание энергии в системе и энтропия минимальны и определяются надлежащим порядком в экономической системе.

\section{3. Диссипативный порядок \\ в экономической системе: основные показатели и условия поддержания}

Упорядоченность любой организации измеряется показателем энтропии - состояния системы с позиции внутренней упорядоченности. Чем сложнее система, тем большим порядком и эффективностью она обладает. Уровень энтропии в такой системе минимален. Порядок позволяет сократить потери энергии, повысить эффективность работы экономической системы, достичь большего синергетического эффекта за счёт самовзаимодействия элементов системы. Основатель понятия синергетического эффекта Г. Хаккен определяет порядок в системе как правила и условия взаимодействия элементов в системе. Основное условие «синергетического эффекта», по его мнению, - это наличие должного порядка в системе [18]. Другой основатель, но уже «диссипативного пространства», И. Пригожин считает, что чем сложнее порядок, тем система более эффективна [21].

Наличие порядка в классической экономической системе характеризуется наличием следующих признаков: 1) очередность расположения или действия элементов; 2) соответствие требованиям, критериям, стандартам (законам); 3) распределение функций, ресурсов по утвержденной структуре; 4) подчинение по утвержденной иерархии; 5) согласованность действий и целей. По мере нарастания количества элементов порядка в социальной среде нарастает и качество взаимосвязей этих элементов. Однако качество взаимодействия элементов будет снижаться, если установлены не все элементы порядка. Чтобы избежать подобной проблемы, необходимо установить все признаки порядка, что в свою очередь позволит повысить качество их взаимодействия. В ходе исследования авторами было обнаружено, что с целью роста эффективности экономической системы и для появления синергетического эффекта, порядок в диссипативной системе необходимо дополнять еще рядом признаков системы, поскольку класси- ческая экономическая система намного проще диссипативной системы. Такими признаками по приоритетному порядку в диссипативной системе являются: 1) открытость системы; 2) качество принятых законов и правил; 3) безусловное исполнение законов и правил; 4) наличие обратной связи объекта управления с субъектом управления; 5) наличие должной компетенции на всех уровнях иерархии; 6) наполнение организационной структуры группами людей, оказывающих определенное суммарное воздействие на систему по определенным уровням иерархии; 7) наличие работающих лифтов в социальной системе; 8) справедливое вознаграждение.

В праве ли мы рассчитывать сегодня на синергетический эффект в экономической системе РФ? Исследуем состояние признаков порядка для ответа на поставленный вопрос.

1. Открытость системы. Если за основу взять индекс открытого правительства, то в 2017 г. он составил в РФ 0,49 (67-е место в мире), Швеции 0,81, США - 0,73. Индекс инновационной активности - индекс IAK - по этим странам составил: РФ - 19, Швеция - 92, США - 100.

2. Качество принятых законов и правил. По данным аналитического исследования Всемирного банка [22], в России за период с 2006 по 2016 г. индекс качества институтов снизился с 40,2 до 30,7 (максимальное значение 100, в 2016 г. индекс составлял: в США - 91,8, Великобритании - 95,2, Франции - 83,2, Германии - 96,2, Японии - 90,4).

3. Индекс исполнения законов (верховенства законов) в России за период с 2006 по 2016 г. увеличился незначительно - с 18,7 до 21,2. При этом в США индекс составлял 92,3, Великобритании 91,8, Франции - 89,4, Германии - 91,3, Японии 88,5, Финляндии - 99 [там же].

4. Наличие обратной связи с управляемым объектом. В закрытых системах и без обратной связи синергетический эффект невозможен. Если система управления закрыта, то обратная связь отсутствует.

5. Наличие должной компетенции на всех уровнях иерархии. Статистической информации нет, но на размышления наводит непрофессиональный состав правительства РФ с многочисленными заместителями, руководство Газпрома, ЦБ, Сбербанка, Роснефти и т. д.

6. Наполнение организационной структуры группами работников, оказывающих определенное суммарное воздействие на систему по определенным уровням иерархии. Такие суммарные 
воздействия названы синергиками, синкретикамии, энтропиками [21].

Синергики - это такие цели, мотиваторы, компетенции, ресурсы, которые создают в организации конструктивное напряжение, инновационность и проактивность (опережающую активность), ориентацию на максимальные достижения с множественным эффектом.

Синкретики характеризуют порядок и меры по его поддержанию, охранительное действие по удержанию целостности, постоянства, преемственности состояния, управляемости.

Энтропики - это факторы и силы ослабления или разрушения порядка, силы деструктивного напряжения, рассогласования с последующими потерями, разнообразной дезорганизацией.

Данные силы действуют в каждой организации одновременно и взаимодействуют слаженно или противоречиво. Каждая сила имеет свое значение: синкретики обеспечивают стабильность, противодействуют энтропикам, а синергики обеспечивают прогресс. Эти «роли» не должны постоянно закрепляться за названными силовыми векторами: все зависит от стадии развития организации, состояния внешней среды и других условий. Некоторые синергики могут переходить в синкретики и даже в энтропики. Сила воздействия данных групп во многом зависит от доминирования их по уровням власти. Проведенный анализ показывает доминирование энтропиков в верхних эшелонах власти, а синергетиков - в нижней части иерархии. В сложившейся модели доминирования энтропиков на высших иерархических уровнях синергетический эффект невозможен.

7. Наличие работающих лифтов и фильтров в социальной системе, повышение по службе исключительно за профессиональные заслуги и знания и на конкурсной основе. Присутствует в малой степени (35\%). В основном развиты протекционизм, кумовство, комфортность руководителя, родственные связи и патернализм.

8. Справедливое вознаграждение. Зависимость заработной платы от результатов работы. Специалисты Credit Suisse присудили России первое место в рейтинге наиболее неравномерных экономик мира. По их подсчетам, 1 \% населения РФ владеет 74,5 \% благосостояния страны. На втором месте была Индия, где в руках $1 \%$ жителей находилось 58,4 \% богатства страны, на третьем Таиланд - 58 \%. В 2017 г. индекс Джини в РФ составлял 0,42; Германии - 0,31: Норвегии - 0,25.

В связи с этим порядок в экономической системе определяют качество принятых законов и пра- вил и исполнение данных правил. В первую очередь качество взаимодействия элементов среды определяется социальным порядком в экономической системе. Основные признаки порядка, определяющие качество взаимодействия элементов среды, ранжируются «по нарастающей». Подобное ранжирование позволяет оценить достигнутый уровень качества и принять меры по его повышению. Для создания условий самоорганизации в целях возникновения синергетического эффекта в экономической системе необходимо выполнять следующие условия: обеспечить открытость системы, наличие обратной связи, наличие должной компетенции на всех уровнях иерархии, соблюдение иерархии, согласованность действий и целей, подчинение по утвержденной иерархии, справедливое вознаграждение.

Внутри организации происходят сложные процессы на основе взаимодействия таких ее элементов, как ценности, цели, правила, связи, решения, мотиваторы, ресурсы. Взаимодействие этих элементов может быть направлено в положительную сторону, укреплять организацию и способствовать ее процветанию, стабилизировать существующее положение, а может оказывать негативное влияние.

Согласно методологии исследования эффективности и качества государственного управления, предложенной Всемирным банком, используются шесть показателей (индексов Worldwide Governance Indicators), отражающих различные параметры.

1. Voice and Accountability - мнение населения и подотчётность государственных структур. Индекс отражает основные аспекты политических прав, гражданских свобод, политических процессов. Измеряется степень участия населения страны в выборах различных органов власти, включая правительство, независимость прессы, уровень свободы слова.

2. Political Stability and Absence of Violence уровень политической стабильности и отсутствия насилия. Индекс показывает, насколько стабильны государственные институты, какова вероятность существенных перемен, дестабилизации обстановки, изменения политического курса, смены правительства не предусмотренными конституцией страны способами.

3. Government Effectiveness - уровень эффективности работы правительства. Индекс отражает, насколько качественно оказываются государственные услуги. Исследуются уровень доверия граждан к внутренней политике правительства, качество внутренней политики государства, работы аппарата государственного управления, деятельности 
государственных служащих, степень независимости чиновников от политического курса и давления.

4. Regulatory Quality - уровень качества законодательства страны. Индекс отражает способности федерального правительства к качественной формулировке и реализации правовых актов, допускающих наличие в стране частного сектора и способствующих его развитию. Выявляются меры, противоречащие рыночной экономике, включая чрезмерный и неадекватный контроль цен, бизнеca, банковской сферы, торговых отношений и пр.

5. Rule of Law - уровень верховенства закона [23]. Индекс отражает уровень уверенности хозяйствующих субъектов в действующих законах, степень соблюдения этих норм, предсказуемость законодательной власти, уровень преступности, отношение к исполнению договорных обязательств, эффективность деятельности правоохранительных органов и судебной системы.

6. Control of Corruption - уровень сдерживания коррупции. Индекс, отражающий восприятие коррупции в обществе, уровень участия элит в коррупции, степень использования государственной власти в корыстных целях, коррупцию на высшем политическом уровне, воздействие коррупции на экономику страны.

Несмотря на большое число различных показателей, порядок в экономической системе в первую очередь зависит от законов и нормативных актов, регулирующих систему (далее институтов), а также степени их исполнения и соответствие профессиональной компетенции управленцев уровню решаемых задач. Качество институтов и их исполнение (верховенство закона) по странам определяется международными статистическими службами. В частности, по данным аналитического исследования Всемирного банка, в России за период с 2006 по 2016 г. индекс качества институтов снизился с 40,2 до 30,7 (максимальное значение 100, в 2016 г. индекс составлял: в США - 91,8, Великобритании 95,2, Франции - 83,2, Германии - 96,2, Японии $90,4)$. Индекс исполнения законов (верховенства законов) в России за период с 2006 по 2016 г. увеличился незначительно - с 18,7 до 21,2 (максимальное значение 100, в 2016 г. индекс составлял: в США 92,3, Великобритании - 91,8, Франции - 89,4, Германии - 91,3, Японии - 88,5, Финляндии - 99) [22]. Также следует особо обратить внимание на показатель открытости системы управления и наличия обратной связи с управляемым объектом, поскольку в закрытых системах и без обратной связи синергетический эффект невозможен.
Таким образом, приведённые индексы качества и исполнения законов свидетельствуют о крайне низком уровне развития организационной системы в России, серьёзном отставании от развитых стран мира и низком уровне должного порядка в системе в целом. Существующая организационная система в России не соответствует вызову современной экономики и отстала на 30-40 лет от требований времени.

Интегральный показатель порядка в России (рассчитанный как среднее геометрическое индексов качества и исполнения законов) также имеет крайне низкое значение - 25,5, что свидетельствует о фактическом отсутствии должного порядка в экономической системе. В развитых странах, в том числе США, Великобритании, Франции, Германии, Японии, Финляндии, где экономический рост достигает 2-3 \% и более [12, с. 259], интегральный показатель порядка в системе составляет в среднем 91,7. Следовательно, ускорение темпов роста российской экономики во многом зависит от качества и исполнения институтов в системе. С учетом вышесказанного моделирование темпов роста национальной экономики имеет следующий вид:

$$
\frac{d V}{d t}=\frac{d A}{d t} \times \frac{d B}{d t} \times \frac{d U}{d t} \times \frac{d G}{d t} \times \frac{d \sqrt{C P}}{d t},
$$

или

$$
V=(A \times B \times U) \times G \times \sqrt{C P},
$$

где $V$ - объем ВВП в денежном выражении; $A-$ качество институтов; $B$ - индекс исполнения законов; $G$ - индекс инновационной активности - индекс IAK; $C$ - оборудование в денежном выражении; $P$ - количество работающих в производстве; $U$ - открытость экономики.

При исследовании влияния обилия природных ресурсов на размер ВВП по группе нефтегазовых стран с сильными и слабыми институтами были получены самые важные, с точки зрения авторов, результаты. Так, в группе нефтегазовых стран с высокоразвитыми институтами было установлено положительное влияние природных ресурсов на размер ВВП. В группе же стран со слабыми институтами обилие сырья не влияет на уровень ВВП - ни положительно, ни отрицательно. Низкий уровень развития нефтегазовых стран со слабыми институтами объясняется более высоким влиянием институционального развития на ВВП (на душу населения) по сравнению с несырьевыми. По этой причине при высоком качестве институтов нефтегазовые страны способны добиться более высоких результатов экономического развития, чем несырьевые. 
С другой стороны, при низком качестве институтов отставание в развитии нефтегазовых стран также будет выше, чем в несырьевых. Анализ влияния отдельных параметров институциональной среды на размер ВВП на душу населения в нефтегазовых странах показал, что уровень развития институциональной среды имеет значимое влияние на развитие экономики (в частности, размер ВВП на душу населения) через структуру управления, лицензирование, налогообложение, структуру собственности, неравномерное распределение доходов, коррупцию и малую эффективность управленческих решений. При повышении уровня институционального развития страны можно говорить о росте размера ВВП на душу населения: Швейцария - 79242 долл./чел., Норвегия - 70392 долл./чел., Исландия 59629 долл./чел., США - 57436 долл./чел., Россия 8929 долл./чел. [24].

Высокое качество институтов в развитых странах (в частности, в Германии показатель равен 96,2, Великобритании - 95,2, США - 91,8, Японии - 90,4, Франции - 83,2) генерирует негэнтропийные процессы в экономической системе. Низкое качество институтов в РФ (индекс $=30,7)$ создает условия для энтропийных процессов в системе. Вместо предприятий качественного роста диссипативная среда за счет некачественных институтов начинает формировать предприятия злокачественного роста, что в свою очередь приводит к значительным потерям производственного и человеческого капитала [8] в отраслях (более 69 \%). Учитывая вышесказанное, путь роста национальной экономики во многом зависит от организационного развития экономической системы.

\section{ЛИТЕРАТУРА}

1. Удельный вес инновационных товаров, работ, услуг в общем объеме отгруженных товаров, выполненных работ, услуг. - URL: http://www.gks.ru/wps/wcm/ connect/rosstat_main/rosstat/ru/statistics/science_and_ innovations/science/\#

2. Наука и инновации, финансирование науки из средств федерального бюджета. - URL: http://www.gks. $\mathrm{ru} / \mathrm{wps} / \mathrm{wcm} / \mathrm{connect} /$ rosstat_main/rosstat/ru/statistics/ science_and_innovations/science/\#

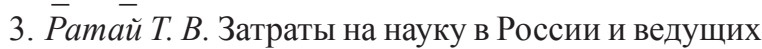
странах мира / Т. В. Ратай // Наука, технологии, инновации. Институт статистических исследований и экономии знаний НИУ ВШЭ. - 2016. - С. 1-3.

4. The labour force in the countries in 2015. - URL: https://www.cia.gov/library/reports

5. Прогноз социально-экономического развития Российской Федерации на 2016 г. и на плановый период 2017-2018 гг. - URL: http://economy.gov.ru/minec/activity/ sections/macro/prognoz
Ключевой проблемой неэффективности отечественной экономической системы является отсталость существующих институтов и отсутствие синергетического порядка в организационной структуpe [25]. Одной из главных институциональных проблем в экономике РФ является регулирование взаимодействия между государством и бизнесом, которое осуществляется уголовным правом, во всех передовых странах мировой экономической системы это взаимодействие регулируется в поле административного права. Регулирование уголовным правом существенно сокращает поле деятельности бизнеса за счет взимания дополнительной ренты чиновниками и правоохранительными органами. Проведенные авторами исследования показали основную причину неудач экономической системы РФ - это отсталость организационной структуры управления бизнесом от современных требований. По мнению авторов, сложившаяся ситуация объясняется сохранившейся от СССР привычкой управлять всеми процессами, поскольку страна в основном управляется бывшими работниками райкомов. Сегодня для создания синергетической экономики в РФ необходим революционный шаг в сторону самоуправляемых синергетических систем с высочайшей эффективностью и созданием новых качеств. Чиновники в новой модели должны решать только социальные проблемы и защищать граждан своей страны от чрезмерной алчности бизнесменов институциональными методами. Мы не должны забывать о существовании «стрелы времени» - организационные структуры экономики необходимо постоянно совершенствовать с учетом новых технических и социальных реалий.

6. Гизатуллин X. Н. Проблемы управления структурными преобразованиями региональной экономики / Х. Н. Гизатуллин, Ф. Н. Гарипов, 3. Ф. Гарипова // Экономика региона. - 2018. - Т. 14, вып. 1. C. $43-52$.

7. На пути к обществу, основанному на знаниях : доклад о развитии человеческого потенциала в Российской Федерации за 2004 г. / под общ. ред. С. Н. Бобылева. - М. : Весь Мир, 2004. - 160 с.

8. Модернизация и развитие человеческого потенциала : доклад о развитии человеческого потенциала в Российской Федерации за 2011 г. / под ред. А. А. Аузана и С. Н. Бобылева. - М. : ПРООН в РФ, 2011. - $146 \mathrm{c}$.

9. The Global Innovation Index 2016 : Winning with Global Innovation, Ithaca, Fontainebleau, and Geneva. Cornell University, INSEAD, and WIPO, 2016. - 451 p.

10. The Global Innovation Index 2017 : Innovation Feeding the World, Ithaca, Fontainebleau, and Geneva. Cornell University, INSEAD, and WIPO, 2017. - 463 p. 
11. Национальные счета, валовой внутренний продукт. - URL: http://www.gks.ru/wps/wcm/connect/rosstat main/ rosstat/ru/statistics/accounts/\#

12. Международный валютный фонд. Перспективы развития мировой экономики : в поисках устойчивого роста - краткосрочное восстановление, долгосрочные задачи. - Вашингтон, октябрь 2017. - 323 с.

13. Lynn R. IQ and Global Inequality / R. Lynn, T. Vanhanen. - Athens, GA : Washington Summit Publishers, 2006. $-442 \mathrm{p}$.

14. Обеспечение устойчивого прогресса человечества : уменьшение уязвимости и формирование жизнестойкости : доклад о человеческом развитии за 2014 г. М. : Весь Мир, 2014. - 239 с.

15. Национальные счета, индексы физического объема. - URL: http://www.gks.ru/free_doc/new_site/vvp/ vvp-god/tab3.htm

16. Прогнозирование социально-экономического развития российских регионов / Г. Ю. Гагарина, Р. В. Губарев, Е. И. Дзюба, Ф. С. Файзуллин // Экономика региона. - 2017. - Т. 13, вып. 4. - С. 1080-1094.

17. Нижегородиеев Р. М. Прогнозирование показателей социально-экономического развития региона / Р. М. Нижегородцев, Е. И. Пискун, В. В. Кудревич // Экономика региона. - 2017. - Т. 13, вып. 1. C. $38-48$.

Пермский государственный нацииональный исследовательский университет

Гершанок А. А., кандидат экономических наук, доиент кафедры менеджмента

E-mail:agershanok@yandex.ru

Мальшев Е. А., доктор экономических наук, профессор кафедры инженернойгеологии и охранын недр

E-mail:dmea@yandex.ru
18. Хаккен Герман. Принципы работы головного мозга : Синергический подход к активности мозга, поведению и когнитивной деятельности / Герман Хаккен. М. : Пер Сэ, 2001. - 314 c.

19. Князева Е. Н. Синергетика : начала нелинейного мышления / Е. Н. Князева, С. П. Курдюмов // Общественные науки и современность. - 1993. - № 2. - С. 38-47.

20. Никитин В. Н. Арт-терапия : учеб. пособие / В. Н. Никитин. - М. : Когито-Центр, 2014. - 328 с.

21. Пригожин И. Порядок из хаоса : Новый диалог человека с природой : пер. с англ. / И. Пригожин ; под общ. ред. В. И. Аршинова, Ю. Л. Климонтовича и Ю. В. Сачкова. - М. : Прогресс, 1986. - 432 с.

22. Worldwide Governance Indicators. - URL: http:// info.worldbank.org/governance/wgi/index.aspx\#reports

23. Новикова E. Н. Верховенство права как вызов времени : монография / Е. Н. Новикова. - М. : Мысль, 2013. -673 c.

24. World Economic Outlook Database. International Monetary Fund. - URL: http://www.imf.org/external/pubs/ $\mathrm{ft} /$ weo/2017/01/ weodata/weorept.aspx

25. Лисичкина Н. В. Синергетика как способ решения проблемы прогнозирования динамики развития сложных социально-экономических систем / Н. В. Лисичкина, Ю. Г. Голоктионова // Фундаментальные исследования. - 2015. - № 7 (ч. 2). - С. 413-417.

Perm State National Research University

Gershanok A. A., Candidate of Economic Sciences, Associate Professor, Department of Management

E-mail:agershanok@yandex.ru

Malyshev E. A., Doctor of Economics, Professor, Department of Engineering Geology and Protection of Bowels

E-mail:dmea@yandex.ru 